\title{
The Need For Training Gender-Sensitive Teachers: Addressing Education Challenges For Gender Sensitive National Development
}

Mutendwahothe Walter Lumadi, North-West University, South Africa Sipho S. Shongwe, University of Swaziland, Swaziland

\begin{abstract}
This study reports on the extent to which colleges of education in Swaziland prepare student teachers to be gender-sensitive in their practice as teachers. Gendering in contemporary teacher education, both primary and secondary was approached from the curricular and agency perspectives. Gender-related differences in the first teacher education curriculum were highly visible. These have persisted and are still visible in the current curricular structures though the wording may have changed over time. Other major findings included factors perceived by lecturers and teacher education management as necessary for implementation of a gendersensitive curriculum in teacher education colleges, and these include the need for gender-related initiatives to address gender issues and the need to address gender hierarchies.
\end{abstract}

Keywords: gender, gender sensitivity, Swaziland, teacher education, curriculum, gendered, pedagogy

\section{INTRODUCTION}

t was just over 70 years ago that teacher education began in Swaziland. It began at the same time for
women and men. Because the guidelines defined for primary teacher education at that time have
remained the essential guidelines, even for later teacher education, it becomes imperative to find the
initial expectations for women teachers then. It is also important to learn what the first curriculum was like and
what its gender system was like. These are pertinent questions addressed in the paper. However, it first provides
some pedagogical background and discusses briefly the contemporary educational situation and the pedagogical
discussions underway in Swaziland at the time before the first stage of teacher education. The main thrust in this
study was to address two combined challenges: 1) the challenge to support student teachers to orient themselves
toward children from the beginning of their studies and 2) the challenge connected with gendering and gender-
sensitive promoting pedagogy.

\section{METHODOLOGY}

The study was designed as a qualitative inquiry using an interpretative framework; hence, interpretative procedures dominated in the analysis. Quantitative and analytical procedures were used in the analysis to complement the interpretative procedures. This section therefore seek to discuss the results as obtained through the student teachers' questionnaire, the lecturers and Ministry of Education personnel, and through policy and official documents from colleges of education. To accomplish this, the data collection instrument items are grouped into themes, which provide answers to the relevant research questions.

\section{Gender in Curricula Structures: A State-Level Historical Perspective}

The emergence of Swaziland's school system included three stages of fundamental changes. The changes appear to have followed the resolutions of societal conflicts between numbers of powerful interest groups. 
The first of the transitions took place in the pre-colonial period. At that time, the missionaries and the 'Swazi traditionalists' both had their conflicting interests in the organisation of instruction in Swaziland. The second phase of transition occurred during the colonial period up to independence (1968). At this time, Swaziland was a British colony administered in the Republic of South Africa. The third period of transition took place after independence when Swaziland was at crossroads where there were conflicting interests of economy and the emerging industry on one hand and the interests of missionaries on the other.

Before the missionary period, Swaziland was a traditional state and the society was stratified along the lines of ruling power. The 'estates' were represented in the traditional echelons of power and the representatives were men. Moving from one social class to another was difficult. The majority of the people were farmers who worked in their rural homes. Division of labour was strictly along the lines of gender. Men were responsible for providing for their families while women raised children and looked after their homes. This trend continued even after the coming of the 'wage' era.

The introduction of 'western' education in Swaziland in the twentieth century further strengthened this dichotomy between males and females. Education and salaried jobs were almost exclusively the prerogative of boys and men. At first, missionaries were the main organisers of education and the education given by it was based on the principles of Christianity. The actual objectives were to achieve general literacy and such knowledge of the Christian doctrine, as was required for full membership of a congregation. Entrance into this education was possible for both sexes. The missionaries' main interest in the development of education in Swaziland had to do mainly with the need to convert the local people to the Christian religion. The locals were taught how to read and write only so they could read the Bible. Missionary education was not only narrow, but also acted as a way of transmitting Christian values and 'western' values. Missionary education did not concentrate on practical worldly subjects, such as building and carpentry. This compounded the conflicts between the Swazi people and the missionaries as the former felt their 'way of life' was undermined.

The colonial government at the time did not commit itself to developing education in the Protectorate. The narrow scope of missionary education curriculum was soon seen as a letdown by the Swazi people who soon expressed their dissatisfaction and advocated for a broader practical oriented curriculum. This demand led to the building of 'self-help' independent tribal schools at the primary level, initiated by the then rulers. These schools became known as National Schools. The then missionary schools later tried to widen the scope of their curriculum; for example, St. Josephs was opened in 1914 with a practical-oriented curriculum.

It was in 1904 that the colonial government began to show commitment in the education of the 'natives'. The colonial government sought to reform education in the Swazi Protectorate between 1928 and 1945 after it was evident that the missionaries could no longer bear the financial burden of education. In 1935, the colonial government finally took total control of education in the Protectorate, even though a few schools remained under missionaries. The Department of Education was instituted and became responsible for formulating all educational policies and for the supervision of schools. Mr. William Pitcher became the first Director of Education. During all these developments in the education arena, there had been lower-level schooling for girls, especially those from the lower social classes. There was need for change; hence, the establishment of a few girls' schools, like Mbuluzi Secondary School, a boarding school in 1923 that was one of missionary initiatives. The girls of the ruling class were mainly educated in the 'Royal family schools' like Zombodze National School and Swazi National School, respectively.

Vocational education was not extensive. The University of Botswana, Lesotho and Swaziland gave qualifications for higher offices in government, which was mainly male-dominated. From the 1950s onward, the demands to develop vocational education began to grow. The first technical-oriented school opened in 1954 and an agricultural college started at Luyengo as part of the University of Botswana, Lesotho, and Swaziland. Students who enrolled at these institutions were predominantly men. The women were not educated to work outside the home, but in the home. The first women's occupation with actual vocational training and with an idea of working outside the home was that of a nurse, whose education in the Nazarene Mission started in the late 1920s. 
The secondary level boys and girls' school systems seem to have provided an important reference system for the construction of the curriculum for teacher education. The main objective for the education of boys was to prepare them to 'get a job', whereas the girls were educated to 'take care of their families'. Traditionally, it was argued that the calling of a woman was to be a mother, a wife and a homemaker; hence, for girls the emphasis was learning modesty, chastity, diligence, patience and other similar skills. Girls were not kept for long in school, the justification being that girls should be prevented from growing up in the wrong direction. Education, which would not take place within one's social class, could result in such wrong directions.

\section{Gender and Curriculum in Swaziland's First curriculum for Teacher Education}

This section addresses the research question; to what extent were gender equality issues included in the first curriculum of teacher training colleges in Swaziland?

Teacher education in Swaziland began with the opening of the Manzini Nazarene Teacher Training College. It began at the same time for women and men and constituted one of the first forums of vocational education for women. As such, it signified an important breakthrough in the prevailing notion that women were destined to stay at home, although the decision to educate oneself to become a teacher also meant contradictions to these women's personal futures. As Sunnari (1997) puts it so succinctly, the education of female teachers was linked to women's duties to work at home and to raise children. Women's special task in their role of bringing up children was to inculcate basic values needed for the then societal orientation, and to give the children a strong and healthy start for their future.

The teacher education programme was set against such a background as above and therefore emphasised different personal growth objectives for the male and female prospective teachers, as a result there were visible sex-related curricular differences, which emerged in its initial stage. One such area of gender difference was the division of female and male student teachers into teachers for small children and teachers for older children respectively. The female student teachers were oriented to work in the lower and upper primary schools, while the males were oriented to work in the upper schools. This gendered practice led to the belief that primary schools are of lesser value in status as a result males became reluctant to enrol in primary colleges. Teaching in a primary school or lower levels of education has come to be associated with 'women', and this notion evolved to encompass the teaching as a profession.

Another area was the differentiated choice of subjects students had to do. They were subjects that were for each specific gender. These choices were later given value as the most important and the less important because the subjects came to be associated with a certain gender. The meaning and impact of that practice can be interpreted through the theories of difference. Such theories perceive women's situation as different from men's situation.

The difference is explained in terms of biosocial conditioning, institutional socialisation, and socialpsychological linkages (Ruddick, 1989). This echoes Sigmund Freud's Psychoanalysis theory that traces the beginning of biological differences to when children discover their physiological differences. Rossi, (1980) links different biological differences between men and women to different patterns of hormonally determined development over the human cycle. One can argue that the fundamental assumption of biological differences is that the physiological make up of human bodies is the foundation of the social relations of gender. That means biology determines gender, and society reflects what nature determines. With this theoretical background in mind, it is easy to explain the reasons why female students, 'soft' subjects while male students choose 'hard Sciences' subjects. The message carried over is that women's situation are different from men's situation. The difference is explained in terms of biosocial conditioning, institutional socialisation, and social-psychological linkages (Mannathoko, 1997). This strengthens cultural practices that pervade the school system wherein the girl child confronts a socialisation process similar to 'home'. As regards to actual pedagogical studies, the sex-related differences were also clear.

Primarily, the differences did not seem to be based on different assumptions concerning learning by men and women. Instead, they seemed to be connected especially with the tasks in the actual teaching practice. In 
principle, school teaching practice had similar contents for both sexes but more often than not, the female students were relegated to teaching lower classes, while the males were assigned upper classes. This hidden curriculum message was that female students were suited to teaching lower classes, which unfortunately was regarded as of lower status. The sex-related differences in the institution also included differences in the moral code and control. Female and male students were instructed differently. For example, female students had to be protected against immorality and actions that were in contradiction to the prevailing norms. Regulations were stricter for women than for male. One can then conclude that the stricter moral control of women gave them less freedom and made them more subordinated. This subordination has relegated women in general to be followers than take initiatives to be leaders also. The assumption that has been created is that men must lead and women follow. If the curriculum in teacher education is silent on gender issues, this assumption continues and becomes the norm. From the societal viewpoint, the state-level establishment of a coeducational teaching profession and the provision of the necessary education signified a breakthrough in the prevailing notion that women were destined to stay at home. The breakthrough was, however, only partial. The education of female teachers was linked to the women's duties in the home.

\section{Gender in Current Structural and Pedagogical Processes in Swaziland's Teacher Education Colleges}

The question to answer next is to what extent is gender equality issues included in the current curriculum in Swaziland's colleges of education? The researcher concludes that discussions and studies on gender and sexrelated equity issues in the educational setting have been rarely studied in Swaziland compared to countries like South Africa and the Western world. They have also been included only exceptionally in curricula as evident from the data analysis presented elsewhere in the report. The investigation exercise has revealed that schools are comfortable with an ideology of neutrality, which seems to influence the thinking on the topic areas. Okkelmo (1999), who carried out a gender related study in Swaziland, agrees that schools' personnel assume that they treat pupils equally and without sex-related differences. Mazibuko, (1998) is convinced that even those teachers who are determined to treat the sexes equally find it hard to change. The same ideology have characterised the topic area in Swaziland's colleges of education.

Epstein and Johnson (1994:34) capture the mood well:

A school culture of silence exists, which discriminates by failing to recognize differences. It posits a very and unambiguously heterosexual world. In this way, the dominant form is made to appear normal, natural, and the subordinate form perverse, remarkable, and dangerous.

The argument is that failure to address gender inequality issues has made gender bias practices appear normal and cultural, and thus acceptable.

Results from historical documents that established teacher education in Swaziland reveal hierarchies within the system. These hierarchies entrench gender inequalities and have historical roots that can be traced back to the colonial era.

At independence in 1968, most teachers in schools from primary level upwards were female. Other public spheres were dominated by men educated in 'western education' during the colonial period, for instance, the civil service where they worked as clerks and interpreters.

Primary level teaching was always a stepping-stone to other high-level professions for men. Women automatically occupied the 'low' status vacant positions left by men populating the primary school level. It was the result of this 'shift' in occupations, that a pattern was established in student enrolment in primary teacher training institutions.

Almost 40 years after independence, enrolment statistics indicate that women still outnumber men by an average of $65 \%$ in primary colleges. 
The difference in numbers (disparity) may not necessarily indicate gender inequality per se but the message behind. Subrahmanian (1998) is of the opinion that there are limitations of 'gender parity' indicators. One arises from the understanding that measuring access to and participation in education, whilst important, are limited indicators of change in education, as they do not by themselves tell us very much about processes of education. At best, they are first-order outcome indicators. Second, they are 'static' measures.

This investigator agrees with the opinion that formal equality measures numerical 'gaps' between female and male outcomes. The Chief Inspector of Colleges acknowledged in the interview that gender parity is the main focus for the Swazi Government at the moment.

However, for equality to be achieved there is need for a definition that recognises that women and men start from different positions of advantage, and are constrained in different ways. Thus, achievement of substantive equality requires the recognition of 'the ways in which women are different from men ...in terms of the socially constructed disadvantages women face relative to men.' Subrahmanian (1998:4). This in turn depends on other processes, for instance, mechanisms for ensuring equality of treatment as well as equality of opportunity for men and women.

The other process is commitment to non-discrimination, to ensure the erasure of social norms that construct women and men as unequal in value in terms of their contributions and entitlements. Assessing gender equality thus requires assessing whether fundamental freedoms and choices are as equally available to women as they are to men. This involves focusing on pathways to equality, extending the concern with treatment and opportunity to also focusing on agency and autonomy exercised by women in enjoying their freedoms (Subrahmanian, 1998). These are gender equality issues a teacher education curriculum should address if it is to be considered effective and relevant.

Another area of concern revealed by data is that some policies in teacher education institutions at the beginning of the 1980s are still defined by the policies of the 1930s when teacher education started. Such policies include the 'unwritten' but practiced policy of giving female teachers the lower levels/ classes.

This practice can best be understood through the claims of the Socio-psychological theories: Poststructuralism perspective. This theory is applied to loosely linked concepts about meaning, for instance, the manner in which meaning is struggled over, produced and the way it circulates among people. Meaning is viewed as dynamic, shifting as various institutional, cultural, linguistic, and social factors interact. Meaning also affects human subjectivity, which also is viewed as shifting, multifaceted and contradictory (Mannathoko, 1995).

Therefore, the dynamic of having female teachers clustering the lower levels of school education, while their male counterparts cluster the upper levels, though not by compulsion, remains a social and cultural expectation in Swaziland. One can argue that this classification of levels according to their importance to the state and society is contributing to gender stratification because the male students dominate the high status levels and female students are marginalised in low status levels.

Although women are not compelled to teach these lower levels, however, it is an institutional expectation underpinned by the socialised belief that women are best suited to caring and bringing up children. This therefore means that women discursively continue to be viewed as caretakers, both within families and in the traditionally woman-identified professions such as teaching (Yuval-Davis, 1997). These assumptions of mothering, femininity, and teaching continue to have profound impact on the organisation and material practices within schools, as in all other arenas.

Course content with respect to gender in colleges of education is another indication that gender issues are not a priority in teacher education institutions in Swaziland.

The researcher concurs with Rosser, (1990) who believes that curriculum materials that are gender biased in language, content, and/or illustrations reinforce the idea that some fields are gender specific. It is true that preservice teachers need to learn to perceive these usually subtle but powerful cumulative impact of curriculum 
materials on girls' and boys' understanding of the world and their places in it, and to learn to teach in ways that enable students to relate to all aspects of the world without limitation.

One can argue that although the content in most subjects appears to be gender neutral, there is no deliberate effort to address the issue of gender inequality in it. This confirms one of the assumptions that undergird this study which states that stereotypes or biased beliefs, ideas, values, attitudes, images and actions of students in matters related to gender may be perpetuated through curriculum and classroom practices.

In the secondary level college of education in particular, the curriculum of the academic year 1988/89 appears neutral on paper. The descriptions for all subjects offered are the same for both sexes. One can but argue that the disappearance of sex-related differences from the curricular text does not necessarily signify an elimination of sex-related differences from the contents of a subject.

Another indication of gendered socialisation of students in teacher education is when they make their subject choices. Analysis of the choices indicates clearly that male students cluster around 'masculine' subjects (preferably science-based subjects) while female students cluster around 'soft' subjects.

Another disturbing picture data revealed in this study was that lecturers' priority in teacher education institutions was to 'finish' the course outline and prepare students for examinations. They therefore resort to approaches that lead to lecturer-class better known as the 'techinicist approach'. It involves delivering the curriculum prescribed at a higher level as effectively as possible. With such approaches, gender issues are bound to be relegated to the background.

Mannathoko (1995) brings a new perspective to the argument by pointing out that gender-bias perceptions of lecturers on the tension between gender and teaching methods are reinforced by development psychology theories of child centred learning. She argues that an overwhelming majority of male and female lecturers believe that in the classrooms what affects student learning is authoritarian teacher-centred teaching and child-centred teaching methods not gender-sensitive pedagogy. The majority of male and female lecturers are not aware of the fact that in certain contexts it is important to focus on gender matters during the teaching process, rather than learner-centred teaching. This is a plausible observation and has been supported elsewhere in the report with an assertion that gender-related topics can be infused into otherwise gender-neutral courses.

This researcher views the techinicist approach as detrimental to gender equality in the classroom and argues that it develops acceptable adaptable-qualifications like obedience as well as with the qualifications of subordination taught to the female gender by the society as a whole.

In summary, data confirm the conception of the position of gender as one component in determining one's status and position in education. On the basis of the curricular documents, at the change of the special societal tasks included in female teacher hood from the 1900s to the present day, the change seems to be from the task of the 'societal mother' of a modern nation state towards a professionally qualified educator free from a gendered division of tasks (Sunnari, 1997). However, when the processes of everyday studies are included in the observation the picture changes. The idea of 'motherhood' seems to be included in female teacher hood even in the present era of teacher education (Mayer, 1996a). It is, however, as Sunnari (1997:146) puts it "Institutionalised' motherhood: a commitment to serve other people as teachers, in as qualified a way as possible, without a special emphasis on educating mothers for the home."

The above quotation indicates the continuing trend of gendering in teacher education and hence a challenge facing implementers of the curriculum and a challenge for pedagogy.

\section{Factors Associated with Effective Implementation of A Gender-laden Curriculum in Teacher Education Colleges in Swaziland}

The findings indicate that gender issues can be addressed through a full gender course introduced at colleges of education. Sunnari (1997:146) who echoes this in literature posits that: 
"The development of gender sensitivity in pedagogy...means a higher-order and flexible perspective which challenges one to pay attention to gender in order to prevent sexual bias and promote equality and equity in supporting human growth as an everyday pedagogical and context-bound praxis...."

Another factor is the need to eliminate gender hierarchies in teacher education. Gender hierarchy sends the message that males are dominating in leadership positions. Liberal feminism, as a branch of inequality theories explains gender inequality as created by a system that restricts women's access to the "public sphere" by burdening them with 'private sphere' responsibilities like child rearing, housework and support of men. To them, sexism is a key force behind gender inequality. It is composed of discriminatory practices and prejudices against women, responsible for social restrictions and confining them from childhood so that they mature into adulthood as helpless, mindless, and dependent beings (Mannathoko, 1995).

This condition perpetuates the notion that women should remain in their 'private sphere' which Sunnari (1997) labels institutionalised motherhood. This defeat all attempts made to critically reflect on gender biases even in teacher education institutions.

Policy officials in the Department of Teacher Education in Swaziland expressed a view that because there is relatively equal enrolment of the sexes and access to education in Swaziland, gender issues were given the priority within education (Okkelmo, 2003). This poses a problem in the success of a gender-sensitive curriculum as an analysis of the objectives of education from the Ministry of Education revealed that there is no urgency to address gender issues within education.

Another problem raised by the Department of Teacher Education was the unavailability of resources to insert a 'new' programme in the already packed syllabus. Resources needed include funds, personnel, and space to run the course. Personnel need training which will involve funding. An ideal solution to this dilemma could be infusion of gender issues into the different subjects. However, as Moletsane (2004:6) argues about research and curricular interventions in South Africa, teacher educators and feminist scholars' attempt to challenge gender inequality in higher institutions of learning and schools seem uncoordinated. This is true about Swaziland. There is evidence of individual efforts in the form of single modules, one-off lecture slots, or optional courses. Integrated gender equity content across the curriculum is ideal but the least used even internationally. Instead, teacher education programmes tend to use strategies that reinforce rather than reduce gender-stereotyped ideas and genderdisciplinary practices by student teachers, which are subsequently replicated in the classroom.

\section{CONCLUSIONS}

\section{Implications}

Implications from the study are that:

- $\quad$ Teacher Education Institutions' curriculum knowledge is reproducing the dominant patriarchal culture. As argued in preceding sections, curriculum texts and course outlines depict masculine narratives and discourses of male knowledge. Although women are not invisible in curriculum texts, their visibility, and narratives are confined to their role s appendages of men.

- There is a gap between theory and practice concerning gender sensitiveness by some education practitioners in teacher education.

\section{Recommendations}

The following recommendations emerge from the conclusions and implications derived from the findings. These recommendations will generate a debate that will culminate in positive actions taken towards addressing gender issues in the country's education system. Some of the recommendations therefore are outlined below: 
- $\quad$ Teachers and teacher educators should examine their syllabuses with the view of incorporating a gender dimension by: i) including the introductory themes on gender; and ii) by exploring gender issues within some of the topics of existing syllabus.

- That the Ministry of Education in collaboration with external donors should consider a continuity in funding workshops, or programmes designed to make students and teacher educators gender sensitive in the area of instructional materials, teaching approaches and classroom management.

- As part of the implementation of gender-laden education in colleges of education, it is recommended that: a) teacher educators themselves be gender sensitive through gender awareness and sensitisation programmes. b) Teacher educators and teachers should employ engendered patterns of classroom organisation and interaction, and c) engendered teaching approaches be employed.

- $\quad$ Capacity building centres should be established in all educational regions intended to train teachers and teacher educators in gender-laden education.

- $\quad$ Data banks should be established containing useful statistics and publications on gender issues.

- $\quad$ Research should be stepped up in the area of gender with particular emphasis on passing on research skills on gender to participants.

- $\quad$ That the Ministry of education should develop and distribute widely gender sensitising publications with the view of promoting gender awareness and sensitivity in the educational system. These materials should contain important guidelines that can be used by any educationist who wishes to promote gender awareness and sensitivity. For example, a published booklet should highlight how gender awareness and sensitivity could be enhanced among teacher educators, teachers and learners such as: a) conducting workshops, b) introducing engendered classroom organisation and interaction; c) introductory lessons on gender; d) focus on gender issues within the existing syllabus topics; e) introducing gender issues career guidance; f) analysing gender issues in instructional materials and g) conducting research projects on gender issues.

\section{AUTHOR INFORMATION}

Professor M. W. Lumadi is an experienced Curriculum Developer. He has worked at numerous Higher Education and Training institutions in South Africa, such as Westminster College of Education (as Rector), South African College for Teacher Education in Pretoria, University of Venda for Science and Technology, Kingdom International College (as dean), and, currently, North West University (NWU). Since 2003, he has served at various managerial committees in NWU and is currently director of the School of Postgraduate Studies. He is a member of Campus and Institutional Senate, Chairperson of Research, Commissioner of Oath, and Member of Council. Professor Lumadi is also an external examiner for Limpopo, Free State, Johannesburg, Tswane University of Technology, University of South Africa, Walter Sisulu, and Zululand.

Dr. Sipho S Shongwe (PhD; M.Ed; B.Ed; STC) is currently a lecturer in the Faculty of Education at the University of Swaziland. He offers curriculum development courses in the Department of Curriculum and Teaching to both preservice and in-service teachers.

\section{REFERENCES}

1. Epstein, D. and Johnson, R. (1994) On the Straight and Narrow: The Heterosexual Presumption, Homo-phobias and schools. In D. Epstein (Ed) Challenging Lesbian and Gay inequalities in Education. Buckingham: Open University Press.

2. Mannathoko, C. (1997) Gender and the Quality of Life in Botswana Teacher Education Institutions as Workplaces. Paper presented at the Third Biennial National Conference on Teacher education. Gaborone.

3. Mannathoko, C. E. (1992) 'Feminist Theories and the Study of Gender Issues in Southern Africa'. In R. Meena (ed) Gender in Southern Africa: Conceptual and Theoretical Issues, Harare: SAPES books.

4. Mannathoko, C. E. (1994) Democracy in the management of teacher education in Botswana. British Journal of Sociology of Education, Volume 15(4), pp.481-495.

5. Mannathoko, C.E. (1995) Gender, Ideology, and the State in Botswana's Teacher education. (Unpublished Doctoral Dissertation) Birmingham: University of Birmingham. 
6. Mazibuko, E.Z. (1996) The Mediation of Teaching through the Central Curriculum Controls. Unpublished PhD Thesis. Edith Cowen University, Perth: Western Australia.

7. Mbingo, S. (2005) First Mission Review by the International Board of education of Nazarene Teacher Training College. A Review Paper. Manzini Nazarene College.

8. Moletsane, R. (2004) Gender Equality and Teacher Education in South Africa: A Review of the History. [On line] URL: http://iafrica.com/highlife/herlife/features/624620.hmt. [Date accessed: 23/09/2004].

9. Okkelmo, K. F. (1999). Some gender related challenges in primary education in Swaziland. A focus on girls and boys within the classrooms. Education in Africa. Vol. 6, p 211 Report no. 2. Oslo: Institute for Educational Research.

10. Rosser, S. V. (1990) Female-friendly Science: Applying women's studies methods and theories to attract students. New York: Pergamon Press.

11. Rossi, A. (1980). Life-span theories and women's lives. Journal of Women in Culture and Society. 6 (1): 4-32.

12. Ruddick, S. T. (1989). Maternal Thinking: Towards a Politics of Peace. New York: Ballantine Books.

13. Sunnari, V. (1992b) How do Novice Student Teachers select and describe girl and boy pupils. Proceedings. ATEE, the $17^{\text {th }}$ Annual Conference. Lahti.

14. Sunnari, V. (1997) Gendered Structures and Processes in Primary Teacher Education: Challenge for Gender-Sensitive Pedagogy. A Doctoral Dissertation. Universities of Oulu and Lapland. 


\section{NOTES}

